Research Article

\title{
Does Foreign Direct Investment Impact Energy Intensity? Evidence from Developing Countries
}

\author{
Wenming Cao, ${ }^{1}$ Shuanglian Chen, ${ }^{2}$ and Zimei Huang ${ }^{3}{ }^{3}$ \\ ${ }^{1}$ School of Economics and Management, Hunan Institute of Technology, Hengyang, Hunan 421002, China \\ ${ }^{2}$ Guangzhou International Institute of Finance, Guangzhou University, Guangzhou 510006, China \\ ${ }^{3}$ School of Economics and Statistics, Guangzhou University, Guangzhou 510006, China \\ Correspondence should be addressed to Zimei Huang; 2111864007@e.gzhu.edu.cn
}

Received 18 August 2019; Revised 24 November 2019; Accepted 22 February 2020; Published 29 March 2020

Guest Editor: Filipe J. Marques

Copyright (c) 2020 Wenming Cao et al. This is an open access article distributed under the Creative Commons Attribution License, which permits unrestricted use, distribution, and reproduction in any medium, provided the original work is properly cited.

The paper presents the results of a study that attempts to investigate the impact of foreign direct investment (FDI) on energy intensity by constructing panel regression model and panel smooth transition regression (PSTR) model. Based on panel data from 1990 to 2014, this study contributes to conduct the impact of FDI on energy intensity from the perspective of emerging country, including BRICS and non-BRICS countries, and investigates the channels of influence of FDI on energy intensity. Besides that, we intend to employ the PSTR model to reveal the nonlinear mechanism of FDI on energy intensity. Our findings reveal several key conclusions: first, FDI exerts insignificant impact on energy intensity in the emerging countries. Second, the impact of FDI on energy intensity is heterogeneous between BRICS and non-BRICS countries. Third, innovation capacity plays various moderating effects on the relationship of FDI and energy intensity among different types of emerging countries. Furthermore, the nonlinear mechanism of FDI on energy intensity is realized with industrial structure as the transition variable, which plays a different effect on the impact of FDI on energy intensity between different samples.

\section{Introduction}

The impact of foreign direct investment (FDI) on energy intensity has been paid more attention over the past few years. Many emerging economies are growing very rapidly and as economic growth increases so too does the demand for energy [1]. Energy is used in the production of almost all goods and services, and it is thus crucial to have a good understanding of the determinants of energy demand [1]. Moreover, improving energy use efficiency has been regarded as a key component of sustainable development that would tackle energy security and poverty [2]. At the same time, FDI is a flow traditionally associated with transfer of knowledge, technology, and management practices and systems from the home countries of multinational enterprises to their host countries $[3,4]$. And it is considered as the most important factor of decreased energy intensity in emerging market economies. Therefore, understanding the impact of FDI on energy intensity has important policy implications. A handful of empirical studies that examine the relationship between FDI and energy intensity mainly focus on the following three aspects.

Firstly, vast literature have investigated the relationship between FDI and energy consumption. Literature on relationship between FDI and energy consumption are inconclusive. On the one hand, FDI plays no significant impact on energy consumption. Sadorsky [1] used a GMM methodology to analyse the impact of FDI on energy consumption in 22 emerging countries. They failed to find any significant relationship between FDI and energy consumption. On the other hand, FDI plays a positive impact on energy consumption. Paramati et al. [5] employed robust panel econometric techniques to investigate the impact of FDI on clean energy use across 20 emerging market economies, spanning the period 1991-2012. The empirical results displayed that FDI has a significant positive impact on clean energy consumption. Furthermore, Doytch and Narayan [3] employed a Blundell-Bond dynamic panel method to 
examine the impact of FDI on renewable- and nonrenewable industrial energy in 74 countries for the period 1985-2012. They pointed that FDI contributes to reducing the usage of nonrenewable energy. Pao and Tsai [6] used a panel cointegration technique to find a long-run equilibrium relationship between emissions, energy consumption, FDI, and real output for the BRIC countries. Adom et al. [7] revealed a robust concave effect of FDI on energy consumption by employing the simultaneous system generalized method of moments estimator to investigate the nexus between energy demand and FDI in Africa.

Secondly, a large body of studies have examined the impact of FDI on energy intensity. Empirical evidences on the effect of FDI on energy intensity are contradictory. First and foremost, FDI plays a negative impact on energy intensity. Mielnik and Goldemberg [8] showed a clear decline in the energy intensity as FDI increases and attributed this effect to the introduction of modern technologies in 20 developing countries. Elliott et al. [9] discovered a significant and negative relationship between the FDI and energy intensity, but the effect varies by geographic location, which reflects differences in the ability of regions to absorb and benefits from environmental spillovers. Sbia et al. [10] employed the autoregressive distributed lag bounds testing approach to explore the relationship between foreign direct investment, clean energy usage, trade openness, carbon emissions, economic growth, and energy demand. They found that foreign direct investment, trade openness, and carbon emissions decline energy demand. Besides that, FDI plays no significant impact on energy intensity. Hübler and Keller [11] conducted a panel study based on a fixed effects methodology and discovered that FDI inflows have no significant impact on energy intensity for 60 developing countries. Ting et al. [12] employed the Logarithmic Mean Divisia Index model to decompose the energy consumption intensity into FDI scale effect, FDI structure effect, and FDI technology effect. The results showed that the FDI scale effect reduces the energy intensity, while FDI structure and technology effect fluctuate and do not promote the reduction of energy consumption intensity. Sadorsky [1] investigated the relationship between FDI and energy demand, and the results indicated that FDI has no much impact on energy demand in emerging economies.

Furthermore, various literature focused on the determinants of energy intensity. For example, Adom and Amuakwa-Mensah [13] regarded FDI, economic structure, trade openness, income, and real crude oil price as the influential factors of energy intensity. Adom [14] analysed the determinants of energy intensity based on the fully modified OLS and canonical cointegration regressions. They considered FDI, price of energy, trade openness, and industry structure as the key determinants of energy intensity. Another research of Adom [15] investigated the relationship of energy intensity and its four influential factors, including industry value-added, economic integration, FDI inflows, and price of energy. Li and Lin [16] argued that industrial structure, technological progress, and energy price are the main factors in influencing the energy intensity. Moreover, some important factors such as innovation, economic development level, total factor productivity, R\&D inputs, proportion of renewable energy consumption, management skills, technology indices, and energy structure have also been documented, in explaining energy intensity. Aller et al. [17] considered the share of industrial output in GDP, ratio of state investment to GDP, and Chinese stock market capitalization as a percentage of GDP as the key factors of energy intensity. Shen et al. [18] regarded technical gap, human capital, R\&D intensity, R\&D spillover, FDI intensity, foreign trade, infrastructure, industrial structure, marketization index, regulation on carbon intensity, and government size as the important determinants of energy intensity.

The impact of FDI on energy intensity remains debatable worldwide because of its mixed empirical results. The reason for these contradictory results may be that much of the previous literature has not studied the impact of FDI on energy intensity under different samples. Therefore, we expand and supplement the existing literature from the following aspects. Firstly, our study attempts to conduct the impact of FDI on energy intensity from the perspective of emerging country, including BRICS and non-BRICS countries. Besides that, we investigate the channels of influence of FDI on energy intensity. Furthermore, we intend to employ the panel smooth transition regression (PSTR) model to reveal the nonlinear mechanism of FDI on energy intensity, which can enrich the theoretical research on energy intensity.

The remainder of the paper is organized as follows. Section 2 presents the hypotheses. Section 3 briefly describes the data, panel regression model, and empirical analysis of impact of FDI on energy intensity. Section 4 presents panel smooth transition regression model and the empirical results. Conclusions are drawn and discussed in Section 5.

\section{Hypotheses}

Hypothesis 1. FDI has a negative influence on energy intensity, and the effect may be heterogeneous in different emerging countries.

FDI plays an important role in modernizing the economy and promoting economic growth in developing countries. FDI can stimulate economic growth through technology transfer and diffusion, spillover effects, productivity gains, the introduction of new processes, and managerial skills [19-22]. Horizontal (or market-seeking) FDI reacts to market size, while vertical (or efficiencyseeking) FDI reacts to technical endowment [23]. With the opening of the economy and development of emerging markets, emerging countries are likely to introduce FDI [24]. The entrance of FDI will bring better management practices, advanced enterprise system, and business philosophy to improve energy use efficiency of host countries and reduce energy intensity. Furthermore, the effect of FDI on energy intensity may be heterogeneous in different emerging countries, such as BRICS and non-BRICS countries. One of the explanations would be that the benefits from FDI are various because of the different absorptive capacity among emerging countries with different economic development levels. The absorptive capacity of host countries, that is, their 
ability to utilize FDI from home countries to reduce their energy intensity, has been found to be an important determinant for whether or not host countries benefit from FDI [25]. Because BRICS countries achieved a more advanced economic development level than non-BRICS countries, absorptive capacity of BRICS countries is better than non-BRICS countries. That is to say, BRICS countries can absorb the management practices, advanced enterprise system, and business philosophy more effectively to improve their production skills and thus reduce energy intensity. Therefore, FDI has a negative impact on energy intensity, and this impact may be heterogeneous in different emerging countries because of their different absorptive capacities.

Hypothesis 2. The impact of FDI on energy intensity may be moderated by innovation capacity, and the moderating effects are various in different emerging countries.

FDI generally is regarded as an important source of capital and financing research and development activity across countries, which can enhance technological innovation ability of the host countries. FDI inflows may introduce new technologies and innovations to firms for the production activities, as well as for the use of energy. The innovative technologies embedded in FDI can lead to overall efficient use of energy. Besides that, when the innovative technologies were absorbed in host countries, they will reduce transactions between departments, optimize collaboration costs and resource allocation efficiency, and reduce energy consumption. That is to say, the impact of FDI on energy intensity will be moderated by innovation capacity. Furthermore, the moderating effect of innovation capacity may be different in various emerging countries, which depends on their technology absorptive capacity. Different developing countries show considerable differences in ability to absorb and benefit from technology transfers. The higher the technology absorptive capacity, the more the innovations are absorbed and created, the less the energy intensity. The countries with a higher absorptive capacity will create innovative products to target new market segments and enter new foreign markets, thus renewing their operations to reduce the energy intensity. In sum, the impact of FDI on energy intensity will be moderated by innovation capacity, and the moderating effect may be various in different emerging countries.

Hypothesis 3. Industrial structure is the influencing mechanism on FDI influencing energy intensity, and the effect may be heterogeneous in different emerging countries.

Energy intensity is largely related to the changes in the structural composition of the economy, which tends to shift towards less energy-intensive sectors. In the industrialization stage, the infrastructure network is built up to facilitate mass production and mass consumption. Because its initial capital stock is associated with industrialization, which can increase energy intensity, it eventually reaches a saturation point, where the consumption of materials is more oriented to replacement [26]. Two key determinants of the change in industrial structure of emerging countries were the relocation of heavy industry from developed countries and a proliferation of foreign joint ventures in energy-intensive industries. And it is not only just to satisfy local demand in developing countries but also to serve global export markets, where the demand for energy-intensive outputs was also increasing. The emerging countries transfer advanced technologies, introduced by FDI, to their production activity and improve their quality of production. Furthermore, specialized division of industry enhances interaction and linkage between companies in the industry chain. Technology transfers and economies of scale might turn out to be more acceptable than new regulatory frameworks that promote the participation of emerging countries. The structural improvements and increasing imports of energyintensive goods will decline energy intensity. Thus, improved technology will spread among domestic peers through competition and cooperation. Furthermore, the spread of improved technology accelerates the improvement in quality of production and reduces energy intensity. Furthermore, owing to the different industrial structures in different emerging countries, the effect of FDI on energy intensity may be heterogeneous. Therefore, industrial structure may be regarded as the influencing mechanism of FDI on energy intensity, and the effect may be heterogeneous in different emerging countries.

\section{Empirical Analysis of Impact of FDI on EI}

This section discusses panel regression results of the impact of FDI on energy intensity. First, we describe the data and variables used in our empirical analysis in Section 3.1. Then, in Section 3.2, we briefly introduce the panel regression model. We investigate the impact of FDI on energy intensity and explore the heterogeneity between BRICS and nonBRICS countries in Section 3.3. In Section 3.4, we further investigate the different impacts of FDI on energy intensity moderated by innovation capacity.

3.1. Data and Variables. The selections of the sample period and countries in our study are based on the availability of annual data, spanning the period 1990-2014. This study makes use of a balanced panel data set of 16 emerging countries to investigate the impact of FDI on energy intensity. According to the huge difference of FDI and energy intensity among countries, we divide the sample into two subsamples: BRICS and non-BRICS countries. The BRICS countries include 5 countries: Brazil, Russia, India, China, and South Africa. The BRICS economies group is recognized as the most developed economies from the emerging economies. They have acquired an important role in the world economy as producers of goods and services. BRICS countries prominently attract larger capital because of their larger potential consumer market having the common characteristic of large population [27]. The non-BRICS countries include Argentina, Chile, Egypt, Indonesia, Iran, Mexico, Malaysia, Philippines, Poland, Thailand, and Turkey. The data are obtained from World Bank, World 
Intellectual Property Organization (WIPO) Statistics Database, and Easy Professional Superior (EPS) macrodatabase.

The explained variable of the panel regression model is energy intensity, while FDI is the explanatory variable. Moreover, to avoid an omitted variable bias, several important control variables are introduced in our model. Control variables added to the model include five ones: innovation capacity, economic development level, trade openness, industrial structure, and energy structure. The measurement and sources of the above variables are as follows.

First, in this study, energy intensity is the explained variable, which is defined as energy consumption per unit of GDP. Energy use depends on socioeconomic and environmental circumstances, such as comparative advantages for energy-intensive activity, resource endowment, population density, and climate [28]. Energy intensity reflects the intensity of energy consumption in general and can be used to conduct country-specific comparative studies. Second, FDI, as an explanatory variable, is expressed by the ratio of net inflows of FDI to GDP. FDI captures the effect of direct technology transfers attributed to foreign investment, which can stimulate economic growth through technology transfer and diffusion, spillover effects, and productivity gains. The entrance of FDI not only brings sufficient capital for the economic development of host countries but also provides research and development funds for the improvement and upgrading of energy technologies and promotes the improvement in energy utilization efficiency, resulting in reduction of energy intensity [29].

Furthermore, we added five control variables to the model. Innovation capacity is a crucial driving force for improvement in energy use efficiency and reduction of energy intensity [30]. Technological innovation plays an important role in optimizing energy structure, promoting resources conservation and recycling, and improving energy utilization efficiency [31]. This indicator is expressed in terms of the natural logarithm of patent applications per million people, and the original data are obtained from the World Intellectual Property Organization statistics database. Economic development level is calculated by the natural logarithm of GDP per capita, which is measured in constant 2010 dollars, because economic development has direct impact on industrial structure and people's consumption preference on energy [32]. Besides that, trade openness, as an indicator of technological diffusion, is measured by the percent of total trade to GDP. The data of economic development level and trade openness are collected from the World Bank. Furthermore, because the energy intensity of different industries varies greatly, industrial structure can reflect the industrial distribution, which is measured by the ratio of output value of the secondary industry to GDP. The higher the proportion of high energy-consuming industries, the more difficult to reduce energy intensity. Moreover, energy structure plays a key role in energy intensity, which is selected as a measure capturing the distribution of energy use [33]. We adopt the share of renewable energy consumption to total final energy consumption to measure the energy structure. The data of industrial structure and energy structure are collected from the EPS macrodatabase. The measurement and sources of variables are described in Table 1.

Table 2 summarizes descriptive statistics for all variables used in our study. Descriptive statistics are presented to describe the basic characteristics of data in this study concerning 16 countries in the period 1990-2014. For each variable, we present the observation, mean, standard deviation (Std. Dev.), minimum (Min), and maximum (Max) of the full and subsample, respectively. As shown in Table 2, there are significant divergences on the range of energy intensity and FDI between BRICS and non-BRICS countries. On the one hand, we focus on energy intensity. Energy intensity of BRICS countries ranges from 0.116 to 1.050 , whereas energy intensity of non-BRICS countries ranges from 0.119 to 0.491 . On the other hand, we concentrate on FDI in different emerging countries. The average FDI in BRICS countries is 0.021 with the minimum value -0.0007 and the maximum value 0.062 . For the non-BRICS countries, this average is 0.025 , ranging from -0.028 to 0.117 . These significant divergences are very closely related to our selection of the samples, which will explain the different impacts of FDI on energy intensity between BRICS and nonBRICS countries.

Furthermore, we conduct a $T$ test before we undertake to investigate the different impacts of FDI on energy intensity between BRICS and non-BRICS countries, which ensure that there is a statistically significant difference between two subsamples. Therefore, we can stratify the sample to further investigate the effect of FDI on energy intensity.

3.2. Panel Regression Model. To investigate the impact of FDI on energy intensity, we specify the panel regression model. Panel regression models are estimated using recently developed techniques like mean group estimators that allow for heterogeneity in the estimation of the slope coefficients. The major advantage of using panel regression model is that this model typically assumes the heterogeneity in the data, which allows us to capture completely by means of individual effects and time effects. And it can provide more efficient estimation and information of impact of FDI on energy intensity. The baseline panel regression model is as follows:

$$
\begin{aligned}
\mathrm{EI}_{i t}= & \beta_{0}+\beta_{1} \mathrm{FDI}_{i(t-j)}+\beta_{2} \operatorname{Inno}_{i(t-j)}+\beta_{3} \operatorname{LnperGDP}_{i(t-j)} \\
& +\beta_{4} \operatorname{Trade}_{i(t-j)}+\beta_{5} \operatorname{Ener}_{i(t-j)}+\beta_{6} \text { Indus }_{i(t-j)}+\varepsilon_{i t}
\end{aligned}
$$

where the subscript $i(t-j)$ indicates country $i$ in time period $t-j . j=0,1,2,3$ is the lag order of each variable, which is dependent on the dynamic correlation coefficient test. EI stands for energy intensity, FDI represents the foreign direct investment, Inno refers to innovation capacity, LnperGDP denotes the economic development level, Trade stands for trade openness, Ener is the energy structure, and Indus refers to industrial structure. $\beta$ denotes a vector of estimated parameters in the equation. $\varepsilon_{i t}$ is the error term. In the baseline panel model, we have not conditioned the impact of FDI on energy intensity. Therefore, 
TABLE 1: Measurement and sources of variables.

\begin{tabular}{|c|c|c|c|c|}
\hline & Variable & & Measurement & Source \\
\hline \multirow{4}{*}{$\begin{array}{l}\text { Explained variable } \\
\text { Explanatory } \\
\text { variable }\end{array}$} & Energy intensity & EI & Total energy consumption/GDP & World Bank \\
\hline & $\begin{array}{l}\text { Foreign direct } \\
\text { investment }\end{array}$ & FDI & Net inflows of FDI/GDP & World Bank \\
\hline & Innovation capacity & Inno & $\log$ (patent applications per million people) & $\begin{array}{l}\text { WIPO Statistics } \\
\text { Database }\end{array}$ \\
\hline & $\begin{array}{c}\text { Economic development } \\
\text { level }\end{array}$ & LnperGDP & $\log ($ GDP per capita) & World Bank \\
\hline \multirow[t]{3}{*}{ Control variable } & Trade openness & Trade & Total trade/GDP & World Bank \\
\hline & Energy structure & Ener & $\begin{array}{l}\text { Renewable energy consumption/total final energy } \\
\text { consumption }\end{array}$ & EPS macrodatabase \\
\hline & Industrial structure & Indus & Output value of the secondary industry/GDP & EPS macrodatabase \\
\hline
\end{tabular}

TABle 2: Descriptive statistics.

\begin{tabular}{|c|c|c|c|c|c|c|c|}
\hline Variable & Sample & Obs & Mean & Std. dev. & Min & Max & $T$ value \\
\hline \multirow{3}{*}{ EI } & 1 & 400 & 0.318 & 0.157 & 0.116 & 1.050 & - \\
\hline & 2 & 125 & 0.439 & 0.201 & 0.116 & 1.050 & \multirow{2}{*}{$-9.342^{* * *}$} \\
\hline & 3 & 275 & 0.263 & 0.089 & 0.119 & 0.491 & \\
\hline \multirow{3}{*}{ FDI } & 1 & 400 & 0.024 & 0.021 & -0.028 & 0.117 & - \\
\hline & 2 & 125 & 0.021 & 0.016 & -0.0007 & 0.062 & \multirow{2}{*}{$2.3669^{* *}$} \\
\hline & 3 & 275 & 0.025 & 0.022 & -0.028 & 0.117 & \\
\hline \multirow{3}{*}{ Inno } & 1 & 400 & 4.156 & 1.083 & 1.330 & 6.523 & - \\
\hline & 2 & 125 & 4.319 & 1.236 & 1.330 & 6.523 & \multirow{2}{*}{$-1.8863^{*}$} \\
\hline & 3 & 275 & 4.081 & 1.000 & 1.843 & 5.701 & \\
\hline \multirow{3}{*}{ LnperGDP } & 1 & 400 & 8.472 & 0.777 & 6.359 & 9.594 & \multirow{3}{*}{$\begin{array}{c}- \\
2.8627^{* * *}\end{array}$} \\
\hline & 2 & 125 & 8.285 & 0.961 & 6.359 & 9.385 & \\
\hline & 3 & 275 & 8.556 & 0.662 & 7.276 & 9.594 & \\
\hline \multirow{3}{*}{ Trade } & 1 & 400 & 0.614 & 0.392 & 0.138 & 2.204 & \multirow{3}{*}{$\begin{array}{c}- \\
9.7165^{* * *}\end{array}$} \\
\hline & 2 & 125 & 0.415 & 0.166 & 0.152 & 1.106 & \\
\hline & 3 & 275 & 0.705 & 0.430 & 0.138 & 2.204 & \\
\hline \multirow{3}{*}{ Ener } & 1 & 400 & 0.211 & 0.160 & 0.004 & 0.587 & \multirow{3}{*}{$-5.653^{* * *}$} \\
\hline & 2 & 125 & 0.281 & 0.177 & 0.032 & 0.587 & \\
\hline & 3 & 275 & 0.180 & 0.141 & 0.004 & 0.586 & \\
\hline \multirow{3}{*}{ Indus } & 1 & 400 & 0.356 & 0.059 & 0.238 & 0.501 & \multirow{3}{*}{$\begin{array}{c}- \\
3.4607^{* * *}\end{array}$} \\
\hline & 2 & 125 & 0.339 & 0.067 & 0.238 & 0.484 & \\
\hline & 3 & 275 & 0.363 & 0.054 & 0.253 & 0.501 & \\
\hline
\end{tabular}

Notes. "Ln" means the variable in natural logarithms; samples 1, 2, and 3 represent full sample, BRICS countries, and non-BRICS countries sample, respectively; ${ }^{* * *},{ }^{* *}$, and ${ }^{*}$ indicate significance at the $1 \%, 5 \%$, and $10 \%$ levels, respectively.

the coefficients in the baseline model show the unconditional impacts of FDI on energy intensity.

To further investigate the impact of FDI on energy intensity, we modify the baseline model by interacting the innovation capacity and FDI variables like equation (2). This is because the impact of FDI on energy intensity will be moderated by innovation capacity:

$$
\begin{aligned}
\mathrm{EI}_{i t}= & \beta_{0}+\beta_{1} \operatorname{FDI}_{i(t-j)}+\beta_{2} \operatorname{Inno}_{i(t-j)}+\beta_{3} \operatorname{LnperGDP}_{i(t-j)} \\
& +\beta_{4} \operatorname{Trade}_{i(t-j)}+\beta_{5} \operatorname{Ener}_{i(t-j)}+\beta_{6} \operatorname{Indus}_{i(t-j)} \\
& +\beta_{7} \operatorname{FDI}_{i(t-j)} * \operatorname{Inno}_{i(t-j)}+\varepsilon_{i t},
\end{aligned}
$$

where the subscript $i(t-j)$ indicates country $i$ in time period $t-j . j=0,1,2,3$ is the lag order of each variable, which is the same as equation (1).
From equation (2), the impact of FDI on energy intensity conditioned on innovation capacity is depicted by the following equation:

$$
\frac{\partial \mathrm{EI}_{i t}}{\partial \mathrm{FDI}_{i(t-j)}}=\beta_{1}+\beta_{7} * \operatorname{Inno}_{i(t-j)} .
$$

From equation (3), innovation capacity enforces the energy-saving impact of FDI if $\beta_{1}>0$ and $\beta_{7}<0$. But, if $\beta_{1}<0$ and $\beta_{7}<0$, a higher innovation capacity rather reinforces the energy-saving impact of FDI. The total impact of FDI will be $\beta_{1}$ if $\beta_{7}$ is not statistically different from zero. However, in the instance where $\beta_{1}$ and $\beta_{7}$ are significant, the total impact of FDI on energy intensity would be evaluated at the mean of innovation capacity.

3.3. Impact of FDI on Energy Intensity. Before investigating the impact of FDI on energy intensity, we conduct the dynamic correlation coefficient test and panel unit root test. 
First, we conduct a dynamic correlation coefficient test for each variable to determine the lag order of variables. The results of dynamic correlation coefficient are presented in Table 3. The results indicate that $\mathrm{FDI}_{t-3}, \mathrm{Inno}_{t-3}$, LnperGDP ${ }_{t}$, Trade $_{t}$, Indus $_{t-3}$, and Ener En $_{t-3}$ are more related to energy intensity. Therefore, we will conduct the empirical analysis of impact of FDI on energy intensity based on variables $\mathrm{FDI}_{t-3}$, Inno $_{t-3}$, LnperGDP $_{t}$, Trade $t$, Indus ${ }_{t-3}$, and Ener $_{t-3}$.

The second one tested for stationarity of all variables used by employing two panel unit root tests: Levin-Lin-Chu (LLC) and Fisher-type tests [34, 35]. Table 4 shows the results of the panel unit root test of all variables. The decision criterion is that the variable is stationary if the unit root tests confirm nonrejection of the null at 5\% level of significance. The results of LLC and Fisher-type tests show that all variables reject the null hypothesis (nonstationary) at 1\% significance level. That is to say, all variables used in this study are stationary.

Table 5 presents the results of impact of FDI on energy intensity. Columns 2, 3, and 4 in Table 5 present the results of panel regression models in full sample, non-BRICS, and BRICS countries, respectively. As seen in Table 5, the results are inconclusive among different samples.

FDI exerts insignificant impact on energy intensity in the full sample. The result is somewhat consistent with the results of Hübler and Keller [11], who discovered that FDI has insignificant effect on energy intensity in 60 developing countries. This insignificant impact of FDI on energy intensity may be closely related to the phenomenon: the impact of FDI on energy intensity is heterogeneous among different emerging countries, such as non-BRICS and BRICS countries. In other words, there may exist significant differences in the impact of FDI on energy intensity between non-BRICS and BRICS countries. Therefore, we further investigate the heterogeneity of the impact of FDI on energy intensity between BRICS and non-BRICS countries.

The impact of FDI on energy intensity is heterogeneous among different samples. First, FDI has a significant and negative effect on energy intensity in BRICS countries. In other words, the increase in FDI will result in the reduction of energy intensity. One of the explanations of this phenomenon is that FDI can stimulate economic growth through technology transfer and diffusion, spillover effects, and productivity gains. The introduction of new processes and managerial skills are beneficial to reduce energy intensity of host countries. At the same time, BRICS countries achieved a more advanced economic development level and better absorptive capacity, which is conducive to absorb the management skills and advanced enterprise system more effectively, improve their production efficiency and energy utilization efficiency simultaneously, and thus reduce their energy intensity. That is to say, FDI has a significantly negative impact on energy intensity in BRICS countries. Second, FDI has an insignificant impact on energy intensity in non-BRICS countries. The reason for the insignificant impact of FDI on energy intensity may be that non-BRICS countries introduce FDI, but their absorptive capacity may be not as good as BRICS countries, resulting in the effects of
FDI are not strong enough to energy intensity in a statistically meaningful way. In other words, FDI has an insignificant impact on energy intensity. Therefore, the impact of FDI on energy intensity is heterogeneous among different samples.

3.4. The Moderating Effect of Innovation Capacity on the Relationship between FDI and Energy Intensity. To further understand how FDI influences energy intensity, we add the interactions of innovation capacity and FDI as explanatory variables, which follow the method of Chileshe [36]. As shown in Table 6, columns 2 and 3 present the results of moderating effect of innovation capacity on the relationship between FDI and energy intensity in BRICS and non-BRICS countries, respectively. The results demonstrated in Table 6 are significant but inconclusive among different samples.

The moderating effect of innovation capacity is various among different samples. On the one hand, innovation capacity plays a positive moderating effect on the negative impact of FDI on energy intensity in BRICS countries. The significance of the interaction between FDI and innovation capacity implies that FDI and innovation capacity do not follow parallel paths. According to the result, a higher innovation capacity weakens the energy-saving impact of FDI. The reasons may be that BRICS countries, who have better innovation capacity, tend to pay more attention to improve their productivity by introducing advanced technologies, managerial skills, and better management practices. The higher the absorptive capacity, the more the innovation are absorbed and created, which results in the increase in energy consumption, improving energy intensity. In sum, innovation capacity has a significant positive moderating impact on the relationship between FDI and energy intensity in BRICS countries.

On the other hand, innovation capacity plays a negative moderating effect on the impact of FDI on energy intensity in non-BRICS countries. That is to say, a higher innovation capacity reinforces the energy-saving impact of FDI. The reason may be that the improvement in innovation capacity is beneficial to improve the efficiency of FDI more effectively in non-BRICS countries. Innovation capacity will help them to improve their technology skills and management capacity introduced by FDI. And it will reduce transactions between department, optimize collaboration costs and resource allocation efficiency, and further improve the energy use efficiency, thus reducing the energy intensity. Therefore, innovation capacity plays a negative moderating effect on the relationship between FDI and energy intensity in nonBRICS countries. In sum, innovation capacity plays different moderating effects on the impact of FDI on energy intensity between BRICS and non-BRICS countries.

\section{The Influence Mechanism of FDI on Energy Intensity}

4.1. Panel Smooth Transition Regression Model. To address the nonlinear relationship between FDI and energy intensity, we specify a panel smooth transition regression (PSTR) 
TABLE 3: Results of dynamic correlation coefficient.

\begin{tabular}{lcccc}
\hline & $t$ & $t-1$ & $t-2$ & $t-3$ \\
\hline FDI & $-0.1941(0.0001)$ & $-0.2001(0.0001)$ & $-0.2110(0.0000)$ & $-0.2152(0.0000)$ \\
Inno & $-0.1599(0.0013)$ & $-0.1595(0.0017)$ & $-0.1622(0.0018)$ & $-0.1660(0.0018)$ \\
LnperGDP & $-0.5436(0.0000)$ & $-0.5380(0.0000)$ & $-0.5318(0.0000)$ & $-0.5264(0.0000)$ \\
Trade & $-0.0443(0.3769)$ & $-0.0367(0.4736)$ & $-0.0319(0.5420)$ & $-0.0273(0.6104)$ \\
Indus & $0.2433(0.0000)$ & $0.2536(0.0000)$ & $0.2586(0.0000)$ & $0.2615(0.0000)$ \\
Ener & $-0.0581(0.2462)$ & $-0.0679(0.1845)$ & $-0.0750(0.1510)$ & $-0.0811(0.1286)$ \\
\hline
\end{tabular}

Notes. $P$ values are showed in parentheses.

TABLE 4: Results of the panel unit root test.

\begin{tabular}{lcc}
\hline Variables & Levin-Lin-Chu test & Fisher-type test \\
\hline EI & $-1.160(0.123)$ & $73.473(0.000)$ \\
FDI & $-6.089(0.000)$ & $132.114(0.000)$ \\
Inno & $-4.022(0.000)$ & $95.259(0.000)$ \\
LnperGDP & $-3.928(0.000)$ & $117.999(0.000)$ \\
Trade & $-3.769(0.000)$ & $102.418(0.000)$ \\
Indus & $-4.034(0.000)$ & $124.065(0.000)$ \\
Ener & $-2.856(0.002)$ & $122.663(0.000)$ \\
\hline
\end{tabular}

Notes. $P$ values are showed in parentheses.

TABLE 5: Results of the panel regression model.

\begin{tabular}{lccc}
\hline & Full & Non-BRICS & BRICS \\
\hline FDI $_{t-3}$ & -0.191 & -0.143 & $-1.122^{* * *}$ \\
& $(0.137)$ & $(0.112)$ & $(0.290)$ \\
Inno $_{t-3}$ & $0.016^{* * *}$ & $0.020^{* * *}$ & $0.067^{* * *}$ \\
& $(0.005)$ & $(0.004)$ & $(0.014)$ \\
LnperGDP $_{t}$ & $-0.208^{* * *}$ & $-0.112^{* * *}$ & $-0.338^{* * *}$ \\
& $(0.012)$ & $(0.011)$ & $(0.024)$ \\
Trade $_{t}$ & $0.031^{*}$ & $0.023^{*}$ & 0.036 \\
& $(0.016)$ & $(0.012)$ & $(0.045)$ \\
Indus $_{t-3}$ & $0.193^{* * *}$ & $0.329^{* * *}$ & -0.054 \\
& $(0.062)$ & $(0.058)$ & $(0.095)$ \\
Ener $_{t-3}$ & $-0.156^{* *}$ & $-0.106^{* *}$ & 0.050 \\
& $(0.064)$ & $(0.050)$ & $(0.185)$ \\
cons & $1.971^{* * *}$ & $1.032^{* * *}$ & $2.965^{* * *}$ \\
$N$ & $(0.109)$ & $(0.100)$ & $(0.196)$ \\
$R^{2}$ & 352 & 242 & 110 \\
\hline
\end{tabular}

Notes. Standard errors are in parentheses. ${ }^{* * *},{ }^{* *}$, and ${ }^{*}$ indicate significance at the $1 \%, 5 \%$, and $10 \%$ levels, respectively.

model, which was introduced by González et al. [37]. Nonlinear effects are widespread in the recent study [38-41]. The PSTR model can accurately describe the transition between the linear and nonlinear models in the process of
TABLE 6: Results of moderating effect of innovation capacity.

\begin{tabular}{lcc}
\hline & BRICS & Non-BRICS \\
\hline FDI $_{t-3}$ & $-0.962^{* * *}$ & -0.067 \\
& $(0.271)$ & $(0.112)$ \\
Inno $_{t-3}$ & $0.069^{* * *}$ & $0.017^{* * *}$ \\
& $(0.013)$ & $(0.004)$ \\
FDI $_{t-3}{ }^{*}$ Inno $_{t-3}$ & $0.868^{* * *}$ & $-0.287^{* * *}$ \\
& $(0.209)$ & $(0.098)$ \\
LnperGDP $_{t}$ & $-0.382^{* * *}$ & $-0.117^{* * *}$ \\
& $(0.024)$ & $(0.011)$ \\
Trade $_{t}$ & $0.088^{* *}$ & $0.027^{* *}$ \\
& $(0.043)$ & $(0.012)$ \\
Indus $_{t-3}$ & 0.030 & $0.290^{* * *}$ \\
& $(0.090)$ & $(0.058)$ \\
Ener & -0.092 & $-0.107^{* *}$ \\
& $(0.175)$ & $(0.050)$ \\
cons $^{*}$ & $3.578^{* * *}$ & $1.167^{* * *}$ \\
$N$ & $(0.221)$ & $(0.106)$ \\
$R^{2}$ & 110 & 242 \\
\hline
\end{tabular}

Notes. Standard errors are in parentheses. ${ }^{* * *},{ }^{* *}$, and ${ }^{*}$ indicate significance at the $1 \%, 5 \%$, and $10 \%$ levels, respectively.

energy intensity by selecting different transition variables or transfer functions $[42,43]$. The PSTR model may be considered as a linear heterogeneous panel model, which allows regression coefficients to vary across individuals and over time. Heterogeneity in the regression coefficients is allowed for by assuming that these coefficients are bounded continuous functions of an observable variable, which called the transition variable [37]. As the transition variable possibly is individual-specific and time-varying, the regression coefficients are allowed to be various for each of the individuals in the panel and to change over time.

In this paper, we define the basic PSTR model with two extreme regimes as follows:

$$
\begin{aligned}
\mathrm{EI}_{i t}= & \alpha 0+\alpha_{1} \operatorname{FDI}_{i(t-3)}+\alpha_{2} \operatorname{Inno}_{i(t-3)}+\alpha_{3} \operatorname{LnperGDP}_{i t}+\alpha_{4} \operatorname{Trade}_{i t}+\alpha_{5} \text { Ener }_{i(t-3)}+\alpha_{6} \operatorname{Indus}_{i(t-3)}+ \\
& \sum_{j=1}^{r}\left(\beta_{1} \mathrm{FDI}_{i(t-3)}+\beta_{2} \operatorname{Inno}_{i(t-3)}+\beta_{3} \operatorname{LnperGDP}_{i t}+\beta_{4} \operatorname{Trade}_{i t}+\beta_{5} \operatorname{Ener}_{i(t-3)}+\beta_{6} \operatorname{Indus}_{i(t-3)}\right) g_{j}\left(\operatorname{In}_{n} d u s_{i(t-3)}^{(j)} ; \gamma_{j} ; c_{j}\right)+\varepsilon_{i t},
\end{aligned}
$$

where $i=1, \ldots, N$ and $t=1, \ldots, T . N$ and $T$ denote the cross-sectional and time dimensions of the panel, respectively. $\mathrm{EI}_{i t}$ represents the energy intensity, FDI represents the foreign direct investment, Inno refers to the 
innovation capacity, LnperGDP denotes the economic development level, Trade stands for the trade openness, Ener is the energy structure, and Indus refers to the industrial structure. $\alpha$ is a vector of estimated parameters in the linear model. $\beta$ denotes a vector of estimated parameters in the nonlinear model, and $u_{i t}$ represents the errors. Two extreme values are associated with regression coefficients $\alpha$ and $\alpha+\beta$. The transition function $g\left(\operatorname{Indus}_{i(t-3)}^{(j)} ; \gamma, c\right)$ is a continuous function of the transition variable industrial structure, which is bounded between 0 and 1 . To explore the differences in the relationship between FDI and energy intensity for values higher or lower than the transition variable, this study employs a logistic transition function as follows:

$$
g\left(\operatorname{Indus}_{i(t-3)} ; \gamma, c\right)=\left(1+\exp \left(-\gamma\left(\operatorname{Indus}_{i(t-3)}-c\right)\right)\right)^{-1},
$$

where the parameter $\gamma$ is the slope of the transition and determines the smoothness of the transitions, i.e., the speed of the transition from one regime to another. The parameter $c$ is the threshold value. In the first regime, Indus $i_{i(t-3)}$ is less than $c$, while in the second regime, Indus $s_{i(t-3)}$ is larger than $c$. The PSTR model provides a parametric approach of the cross-country heterogeneity and the time instability of the coefficients of FDI ${ }_{i t}$, which switch smoothly based on the transition function $g\left(\operatorname{Indus}_{i(t-3)} ; \gamma, c\right)[42,44]$.

4.2. Results of Pretests. Before testing the PSTR model, some pretests were undertaken. The first one tested the linearity or homogeneity, and the second test was done to identify the number of transition functions.

The first step consists of testing the linear specification. The objective of this part is to confirm that there is a nonlinear relationship between FDI and energy intensity. Table 7 presents the linearity test results between FDI and energy intensity based on the statistics of Lagrange multiplier Wald test (LM), Fisher test (LMF), and the likelihood ratio test (LRT). The null hypothesis was $H_{0}: \beta_{1}=0$, and the alternative was $H_{1}: \beta_{1} \neq 0$. When the test results reject the null hypothesis, there is a nonlinear effect between FDI and energy intensity. However, under $H_{0}$, the PSTR model contained unidentified nuisance parameters, and the test was nonstandard. The transition function was replaced by its first-order Taylor expansion round $\gamma=0$. The null hypothesis of this test became $H_{0}: \gamma=0$. This null hypothesis could be tested by the Wald and likelihood ratio tests. The test can be written as

$$
\begin{aligned}
\mathrm{LM} & =\frac{\mathrm{TN}\left(\mathrm{SSR}_{0}-\mathrm{SSR}_{1}\right)}{\mathrm{SSR}_{0}}, \\
\mathrm{LM}_{F} & =\frac{\left(\left(\mathrm{SSR}_{0}-\mathrm{SSR}_{1}\right) / m k\right)}{\left(\mathrm{SSR}_{1} /(\mathrm{TN}-N-m k)\right)}, \\
\mathrm{LRT} & =-2 \log \frac{\mathrm{SSR}_{1}}{\mathrm{SSR}_{0}},
\end{aligned}
$$

where $\mathrm{SSR}_{0}$ is the panel sum of squared residuals under $H_{0}$ and $\mathrm{SSR}_{1}$ is the panel sum of squared residuals under $H_{1}$.
TABLE 7: Linearity tests.

\begin{tabular}{lcc}
\hline$H_{0}: r=0$ vs. $H_{1}: r=1$ & BRICS & Non-BRICS \\
\hline Wald tests $(\mathrm{LM})$ & $50.950(0.000)$ & $42.409(0.000)$ \\
Fisher tests $\left(\mathrm{LM}_{F}\right)$ & $14.237(0.000)$ & $7.968(0.000)$ \\
LRT tests $(\mathrm{LRT})$ & $68.431(0.000)$ & $46.626(0.000)$ \\
\hline
\end{tabular}

Notes. $P$ values are shown in parentheses. Moreover, $r$ is the number of transition functions.

$\mathrm{LM}_{F}$ is assumed to follow Fisher distribution with $m k$ and $\mathrm{TN}-N-m k$ degrees of freedom $(F(m k, \mathrm{TN}-N-m k))$. Under the null hypothesis, all linearity tests follow a chi square distribution with $k$ degrees of freedom $\left(\chi^{2}(k)\right)$.

From the test statistic LM, $\mathrm{LM}_{F}$, and LRT, we can summarize that the null hypothesis is strongly rejected at the $1 \%$ significance level during two samples, indicating that there is a nonlinear relationship between FDI and energy intensity in BRICS and non-BRICS countries.

In the next step, we discuss the number of transitions functions in the model. Table 8 summarizes the results of test of number remaining nonlinear. They show that, according to the results of three tests, both in the BRICS and nonBRICS countries sample, the optimal number of transitions is $\gamma=1$, so there are one transition functions. It means that two-regime PSTR model should be applied in BRICS and non-BRICS countries.

4.3. Results of PSTR Model. In this subsection, we further investigate the impact of FDI on energy intensity between BRICS and non-BRICS countries, with industrial structure as the transition variable. And the estimation of the PSTR model for BRICS and non-BRICS countries is better documented in Table 9.

The nonlinear mechanism of FDI on energy intensity is realized with industrial structure as the transition variable, which is also heterogeneous among different samples. First, FDI has an insignificant impact on energy intensity in the low regime (linear part), but it turns to a significantly negative impact in the high regime (linear part and nonlinear part) in the BRICS countries. From the results of the PSTR model, we find that the slope parameter of the transition function is 14.060 , indicating that the transition between different regimes of BRICS countries is rapid. Besides that, the location parameter of transition function in the BRICS countries is 0.604 . In other words, the two extreme values of the transition function are converted when the institutional distance is equal to 0.604 . When the industrial structure is below 0.604 , the PSTR model tends to the low-industrialization regime. The PSTR model tends to the high-industrialization regime, while industrial structure exceeds 0.604 . We can interpret these results as evidence that BRICS countries are growing very rapidly and reaching more advanced industrialization than other emerging countries. They tend to introduce the advanced technology by FDI to improve their energy use efficiency and productivity and thus reduce energy intensity. This means that the improvement in industrialization will restrain the impact of FDI on energy intensity. 
TABLE 8: Tests of number remaining nonlinear.

\begin{tabular}{lcr}
\hline$H_{0}: r=1$ vs. $H_{1}: r=2$ & BRICS & Non-BRICS \\
\hline Wald tests $(\mathrm{LM})$ & $12.299(0.056)$ & $11.265(0.081)$ \\
Fisher tests $\left(\mathrm{LM}_{F}\right)$ & $1.825(0.103)$ & $1.733(0.115)$ \\
LRT tests $(\mathrm{LRT})$ & $13.042(0.042)$ & $11.536(0.073)$ \\
\hline
\end{tabular}

Notes. $P$ values are shown in parentheses. Moreover, $r$ is the number of transition functions.

TABLE 9: Coefficient estimation of the panel smooth transition regression (PSTR) model: industrial structure.

\begin{tabular}{|c|c|c|c|c|}
\hline & \multicolumn{2}{|c|}{ BRICS } & \multicolumn{2}{|c|}{ Non-BRICS } \\
\hline & Linear & Nonlinear & Linear & Nonlinear \\
\hline FDI & $0.156(0.483)$ & $-14.544^{*}(-1.935)$ & $-0.040(-0.274)$ & $-0.190(-0.906)$ \\
\hline Inno & $0.006(0.369)$ & $0.858^{* * *}(2.659)$ & $-0.004(-0.755)$ & $0.031^{* * *}(3.769)$ \\
\hline LnperGDP & $-0.285^{* * *}(-10.346)$ & $0.210(0.361)$ & $-0.102^{* * *}(-7.786)$ & $-0.011^{*}(-1.694)$ \\
\hline Trade & $0.099^{* *}(1.992)$ & $1.231^{*}(1.698)$ & $0.063^{* * *}(2.655)$ & $-0.037(-1.135)$ \\
\hline Indus & $-0.002(-0.005)$ & $-11.796^{*}(-1.722)$ & $-0.512^{* * *}(-6.034)$ & $0.391^{* * *}(3.443)$ \\
\hline Ener & $0.252(1.396)$ & $-2.649(-1.191)$ & $0.188^{* * *}(3.087)$ & $-0.422^{* * *}(-7.492)$ \\
\hline Location parameters $\mathrm{C}$ & \multicolumn{2}{|c|}{0.604} & \multicolumn{2}{|c|}{0.361} \\
\hline Slope parameters $\gamma$ & \multicolumn{2}{|c|}{14.060} & \multicolumn{2}{|c|}{67.663} \\
\hline AIC criterion & \multicolumn{2}{|c|}{-7.259} & \multicolumn{2}{|c|}{-7.498} \\
\hline BIC criterion & \multicolumn{2}{|c|}{-6.915} & \multicolumn{2}{|c|}{-7.296} \\
\hline
\end{tabular}

Notes. $t$-Statistics are shown in parentheses after the estimated coefficients. ${ }^{*},{ }^{* *}$, and ${ }^{* * *}$ denote statistical significance at the $10 \%, 5 \%$, and $1 \%$ levels, respectively. $\gamma$ is the slope parameter (smooth parameter or transition speed).

Second, FDI has insignificant impact on energy intensity in both the low and high regimes in the non-BRICS countries. The slope parameter of the transition function is 67.663, indicating that the transition function with the industrial structure as the transition variable exhibits a rapid trend. Besides that, the location parameter of transition function in the non-BRICS countries is 0.361 . When the industrial structure is below 0.361, the PSTR model tends to the low-industrialization regime. The PSTR model tends to the high-industrialization regime, when industrial structure exceeds 0.361 . The insignificant result may be because most of non-BRICS countries are in the process of industrialization, and the entrance of FDI may not improve production technology effectively to improve the efficiency of energy utilization. Therefore, FDI plays insignificant impact on energy intensity in both the low-industrialization and high-industrialization regimes in the non-BRICS countries.

\section{Conclusions}

The main objective of this study is to investigate the impact of FDI on energy intensity. To achieve this objective, we first use a panel regression model and divided the full sample into BRICS and non-BRICS countries subsamples to investigate the impact of FDI on energy intensity. Besides that, we investigate the channels of influence of FDI on energy intensity. Furthermore, we intend to employ the panel smooth transition regression (PSTR) model to reveal the nonlinear mechanism of FDI on energy intensity. Based on the empirical results, several important conclusions are drawn as follows.

First, FDI exerts insignificant impact on energy intensity in the emerging countries. Second, the impact of
FDI on energy intensity is heterogeneous between BRICS and non-BRICS countries. Third, innovation capacity plays various moderating effects on the relationship of FDI and energy intensity among different types of emerging countries. A higher innovation capacity weakens the energy-saving impact of FDI in BRICS countries, while a higher innovation capacity reinforces the energy-saving impact of FDI in non-BRICS countries. Forth, the nonlinear mechanism of FDI on energy intensity is realized with industrial structure as the transition variable, which plays a different effect on the impact of FDI on energy intensity between different samples.

Accordingly, the following policy implications can be pursued to reduce energy intensity of BRICS and nonBRICS countries. First, each country should set more effective policies to introduce FDI scientifically because the entrance of FDI will bring advanced technology and capital for innovation. Additionally, non-BRICS countries should improve their absorption ability to make full use of the advanced technology and capital to improve their productivity and energy use efficient, thus reducing their energy intensity. Second, emerging countries should give full play to the resource advantages of technological innovation. In the process of industrial transfer and upgrading, through the expansion of investment and industrial chain integration, it can enhance the necessary technical innovation and service support in some highenergy efficiency industries [45]. Furthermore, panel smooth transition regression results provide the scientific basis for policymakers to target policies to a specific country with different industrialization levels. To conclude, different countries should carry out appropriate entry policies of FDI to improve their energy use efficiency and productivity, thus reducing energy intensity. 


\section{Data Availability}

The data used to support the findings of this study are included within the article.

\section{Conflicts of Interest}

The authors declare that there are no conflicts of interest.

\section{Acknowledgments}

The authors would like to thank tutor Tinghui Li for guiding this research. This research was funded by Research results No. 291(2019) of the Teaching Reform Research Project of Ordinary Universities in 2019 and Hunan Province's 13th Five-Year Education Planning Project in 2019 (Research on the Quantitative Index System and Mathematical Model of Entrepreneurship Education Quality Evaluation in Local Universities of Hunan Province) (XJK19BGD035).

\section{References}

[1] P. Sadorsky, "The impact of financial development on energy consumption in emerging economies," Energy Policy, vol. 38, no. 5, pp. $2528-2535,2010$.

[2] S. Voigt, E. De Cian, M. Schymura, and E. Verdolini, "Energy intensity developments in 40 major economies: structural change or technology improvement?" Energy Economics, vol. 41, pp. 47-62, 2014.

[3] N. Doytch and S. Narayan, "Does FDI influence renewable energy consumption? An analysis of sectoral FDI impact on renewable and non-renewable industrial energy consumption," Energy Economics, vol. 54, pp. 291-301, 2016.

[4] S. Wang, "Impact of FDI on energy efficiency: an analysis of the regional discrepancies in China," Natural Hazards, vol. 85, no. 2, pp. 1209-1222, 2017.

[5] S. R. Paramati, M. Ummalla, and N. Apergis, "The effect of foreign direct investment and stock market growth on clean energy use across a panel of emerging market economies," Energy Economics, vol. 56, pp. 29-41, 2016.

[6] H.-T. Pao and C.-M. Tsai, "Multivariate Granger causality between $\mathrm{CO}_{2}$ emissions, energy consumption, FDI (foreign direct investment) and GDP (gross domestic product): evidence from a panel of BRIC (Brazil, Russian Federation, India, and China) countries," Energy, vol. 36, no. 1, pp. 685-693, 2011.

[7] P. K. Adom, E. E. O. Opoku, and I. K. M. Yan, "Energy demand-FDI nexus in Africa: do FDIs induce dichotomous paths?" Energy Economics, vol. 81, pp. 928-941, 2019.

[8] O. Mielnik and J. Goldemberg, "Foreign direct investment and decoupling between energy and gross domestic product in developing countries," Energy Policy, vol. 30, no. 2, pp. 87-89, 2002.

[9] R. J. R. Elliott, P. Sun, and S. Chen, "Energy intensity and foreign direct investment: a Chinese city-level study," Energy Economics, vol. 40, pp. 484-494, 2013.

[10] R. Sbia, M. Shahbaz, and H. Hamdi, "A contribution of foreign direct investment, clean energy, trade openness, carbon emissions and economic growth to energy demand in UAE," Economic Modelling, vol. 36, pp. 191-197, 2014.

[11] M. Hübler and A. Keller, "Energy savings via FDI? Empirical evidence from developing countries," Environment and Development Economics, vol. 15, no. 1, pp. 59-80, 2010.
[12] Y. Ting, L. R. Yin, and Z. Y. Ying, "Analysis of the FDI effect on energy consumption intensity in Jiangsu province," Energy Procedia, vol. 5, pp. 100-104, 2011.

[13] P. K. Adom and F. Amuakwa-Mensah, "What drives the energy saving role of FDI and industrialization in East Africa?" Renewable and Sustainable Energy Reviews, vol. 65, pp. 925-942, 2016.

[14] P. K. Adom, "Asymmetric impacts of the determinants of energy intensity in Nigeria," Energy Economics, vol. 49, pp. 570-580, 2015.

[15] P. K. Adom, "Determinants of energy intensity in South Africa: testing for structural effects in parameters," Energy, vol. 89, pp. 334-346, 2015.

[16] K. Li and B. Lin, "The nonlinear impacts of industrial structure on China's energy intensity," Energy, vol. 69, pp. 258-265, 2014.

[17] C. Aller, M. J. Herrerias, and J. Ordonez, "The effect of financial development on energy intensity in China," Energy Journal, vol. 39, no. 1, 2018.

[18] X. Shen, B. Lin, and W. Wu, "R\&D efforts, total factor productivity, and the energy intensity in China," Emerging Markets Finance and Trade, vol. 55, no. 11, pp. 2566-2588, 2019.

[19] A. Omri and B. Kahouli, "The nexus among foreign investment, domestic capital and economic growth: empirical evidence from the MENA region," Research in Economics, vol. 68, no. 3, pp. 257-263, 2014.

[20] M. Abdouli and S. Hammami, "The dynamic links between environmental quality, foreign direct investment, and economic growth in the Middle Eastern and North African countries (MENA region)," Journal of the Knowledge Economy, vol. 9, no. 3, pp. 833-853, 2018.

[21] H. Hettige, M. Huq, S. Pargal, and D. Wheeler, "Determinants of pollution abatement in developing countries: evidence from South and Southeast Asia," World Development, vol. 24, no. 12, pp. 1891-1904, 1996.

[22] P. A. Kwakwa, H. Alhassan, and S. Aboagye, "Environmental Kuznets curve hypothesis in a financial development and natural resource extraction context: evidence from Tunisia," Quantitative Finance and Economics, vol. 2, no. 4, pp. 9811000, 2018.

[23] Z. Li, Z. Huang, and H. Dong, "The influential factors on outward foreign direct investment: evidence from the "the belt and road"” Emerging Markets Finance and Trade, vol. 55, no. 14, pp. 3211-3226, 2019.

[24] J. Zhong, M. Wang, B. Drakeford, and T. Li, "Spillover effects between oil and natural gas prices: evidence from emerging and developed markets," Green Finance, vol. 1, no. 1, pp. 30-45, 2019.

[25] S. Girma and H. Görg, "Foreign direct investment, spillovers and absorptive capacity: evidence from quantile regressions," SSRN Electronic Journal, vol. 13, 2005.

[26] P. Sadorsky, "Do urbanization and industrialization affect energy intensity in developing countries?” Energy Economics, vol. 37, pp. 52-59, 2013.

[27] N. Vijayakumar, P. Sridharan, and K. C. S. Rao, "Determinants of FDI in BRICS countries: a panel analysis," International Journal of Business Science \& Applied Management (IJBSAM), vol. 5, no. 3, pp. 1-13, 2010.

[28] J. Cornillie and S. Fankhauser, "The energy intensity of transition countries," Energy Economics, vol. 26, no. 3, pp. 283-295, 2004. 
[29] G. Liao and B. Drakeford, "An analysis of financial support, technological progress and energy efficiency: evidence from China," Green Finance, vol. 1, no. 2, pp. 174-187, 2019.

[30] Z. Li, G. Liao, Z. Wang, and Z. Huang, "Green loan and subsidy for promoting clean production innovation," Journal of Cleaner Production, vol. 187, pp. 421-431, 2018.

[31] Z. Li, H. Dong, Z. Huang, and P. Failler, "Impact of foreign direct investment on environmental performance," Sustainability, vol. 11, no. 13, p. 3538, 2019.

[32] K. Li and B. Lin, "An application of a double bootstrap to investigate the effects of technological progress on total-factor energy consumption performance in China," Energy, vol. 128, pp. 575-585, 2017.

[33] Z. Huang, G. Liao, and Z. Li, "Loaning scale and government subsidy for promoting green innovation," Technological Forecasting and Social Change, vol. 144, pp. 148-156, 2019.

[34] G. S. Maddala and S. Wu, "A comparative study of unit root tests with panel data and a new simple test," Oxford Bulletin of Economics and Statistics, vol. 61, no. S1, pp. 631-652, 1999.

[35] A. Levin, C.-F. Lin, and C.-S. James Chu, "Unit root tests in panel data: asymptotic and finite-sample properties," Journal of Econometrics, vol. 108, no. 1, pp. 1-24, 2002.

[36] P. M. Chileshe, "Banking structure and the bank lending channel of monetary policy transmission: evidence from panel data methods," Quantitative Finance and Economics, vol. 2, no. 2, pp. 497-524, 2018.

[37] A. González, T. Teräsvirta, and D. van Dijk, Panel Smooth Transition Regression Models, University of Technology Sydney, Ultimo, Australia, 2017.

[38] Z. Li, H. Dong, Z. Huang, and P. Failler, "Asymmetric effects on risks of virtual financial assets (VFAs) in different regimes: a case of bitcoin," Quantitative Finance and Economics, vol. 2, no. 4, pp. 860-883, 2018.

[39] G. Rigatos, P. Siano, T. Ghosh, and D. Sarno, "A nonlinear optimal control approach to stabilization of a macroeconomic development model," Quantitative Finance and Economics, vol. 2, no. 2, pp. 373-387, 2018.

[40] M. Qamruzzaman and W. Jianguo, "Investigation of the asymmetric relationship between financial innovation, banking sector development, and economic growth," Quantitative Finance and Economics, vol. 2, no. 4, pp. 952-980, 2018.

[41] Z. Zhang, W. Hu, and T. Chang, "Nonlinear effects of P2P lending on bank loans in a panel smooth transition regression model," International Review of Economics \& Finance, vol. 59, pp. 468-473, 2019.

[42] J. Fouquau, C. Hurlin, and I. Rabaud, "The Feldstein-Horioka puzzle: a panel smooth transition regression approach," Economic Modelling, vol. 25, no. 2, pp. 284-299, 2008.

[43] S. Chen, G. Liao, B. Drakeford, and P. Failler, "The non-linear effect of financial support on energy efficiency: evidence from China," Sustainability, vol. 11, no. 7, p. 1959, 2019.

[44] Y.-B. Chiu, "Carbon dioxide, income and energy: evidence from a non-linear model," Energy Economics, vol. 61, pp. 279-288, 2017.

[45] J.-M. Wang, Y.-F. Shi, and J. Zhang, "Energy efficiency and influencing factors analysis on Beijing industrial sectors," Journal of Cleaner Production, vol. 167, pp. 653-664, 2017. 